\title{
A TRADUÇÃO DA VARIAÇÃO LINGUÍSTICA E O ENSINO DE LÍNGUA ESTRANGEIRA: DA TEORIA À PRÁTICA DOCENTE
}

\author{
Valdecy de Oliveira Pontes
}

\section{RESUMO}

Neste artigo, discutiremos as influências sociolinguísticas de uma sociedade sobre a teoria e a prática da tradução, considerando o ensino de língua estrangeira. Assumimos os pressupostos teóricos dos estudos sobre tradução, variação linguística e ensino propostos por Labov (1972, 1978 e 2003), Mayoral (1998), Guy Cook (1997), O’Malley e Chamot (1990) e M. Sneell-Hornby $(1988,1995)$.

PALAVRAS-CHAVE: Tradução; Sociolinguística; Ensino de Línguas.

\section{Introdução}

P or muitas décadas, a tradução foi, nos materiais didáticos (por recomendações oficiais) e na formação de professores de línguas estrangeiras, um tópico negligenciado. Tal fato contrasta com a realidade da prática docente, em que a tradução é utilizada tanto nas atividades desenvolvidas em aula quanto em provas de avaliação, como observam O’Malley e Chamot (1990). Guy Cook (1997) afirma que a abordagem ${ }^{1}$ de gramática e tradução (que,

1 De acordo com Richard \& Rodgers (1986), abordagem refere-se às teorias sobre a natureza da língua e do aprendizado da língua que servem de fonte para as práticas e princípios no ensino de idiomas. Nesse sentido, abordagem é o termo mais abrangente e engloba os pressupostos teóricos acerca da língua e da aprendizagem. Por outro lado, o método é definido por Harmer (2001, p. 78) como o que "nos permite colocar a abordagem na prática [...]. Métodos incluem vários procedimentos e técnicas como parte de seu corpo padrão". 
como veremos adiante, privilegia a aplicação de regras a palavras isoladas) é utilizada amplamente por professores em aulas de língua estrangeira de todo o mundo, por ser apropriada para grupos numerosos. Ainda segundo o autor, o enfoque comunicativo (cuja ênfase recai sobre funçóes linguísticas), por sua vez, nunca foi aplicado de forma completa nas aulas de muitos países, combinando-se sempre com métodos ou técnicas tradicionais.

Mayoral (1998) afirma serem raros os alunos que chegam às aulas de línguas com a capacidade natural de resolver problemas relacionados à tradução da variação linguística. Nesse sentido, é necessário que o professor proponha atividades que enfoquem o processo tradutório a partir do contexto pragmático-discursivo do material a ser traduzido, uma vez que a função do tradutor consiste em compreender o valor estilístico e sócio-histórico das variedades linguísticas presentes no texto.

Neste trabalho, assumimos os pressupostos teóricos dos estudos sobre tradução, variação linguística e ensino propostos por Labov (1972, 1978 e 2003), Mayoral (1998), Guy Cook (1997), O’Malley e Chamot (1990) e M. Sneell-Hornby $(1988,1995)$. Quanto à forma de apresentação do conteúdo, dividimos nosso texto em duas partes: na primeira, expomos, sucintamente, o referencial teórico adotado, a partir de uma perspectiva aplicada ao ensino; na segunda, refletimos sobre o papel da tradução e da variação linguística no ensino de línguas.

\section{Tradução e ensino de línguas}

No que tange à metodologia utilizada, o ensino de línguas estrangeiras, entendido como especialidade científica com objetivos e instrumentos próprios, se constitui, fundamentalmente, a partir da $2^{\text {a }}$ Guerra Mundial, com importantes precedentes nas últimas décadas do século XIX e nas primeiras do século XX. Ao longo de boa parte do século XIX, a influência do modelo de ensino do latim estende-se para as línguas modernas, através do que conhecemos como abordagem de gramática e tradução. Esta abordagem privilegia a aplicação de regras para a tradução de uma língua a outra, com a aprendizagem de palavras isoladas e com o predomínio da língua escrita sobre a oral. De acordo com Santos Gargallo (1999), ela está ancorada nos seguintes princípios: a) memorização de regras gramaticais; b) tradução direta e inversa; 
c) memorização de lista de vocabulário temático; d) uso da língua materna do aluno.

A oposição ao uso da tradução como técnica didática se deveu à crença de que o uso da tradução em sala de aula causaria interferência negativa da língua materna no processo de ensino-aprendizagem de uma língua estrangeira, ou seja, a utilização da tradução pedagógica impediria o aprendiz de pensar em língua estrangeira. Dessa forma, sugiram novas abordagens para o ensino de línguas para substituir a abordagem de gramática e tradução. A primeira delas, a abordagem direta, predica que se aprende através da língua-alvo e, por isso, a língua materna nunca deve ser usada na sala de aula, recorrendo-se a gestos, mímicas e gravuras para a transmissão de significados. Assim, é usada pela primeira vez no ensino de línguas estrangeiras a integração das quatro habilidades: ouvir, falar, ler e escrever, como observa Leffa (1988).

Além dessa proposta de abordagem de ensino, surgiram outras que proibiam o uso da tradução. A abordagem da leitura expandiu-se pelas escolas secundárias dos Estados Unidos na década de 1930, tendo permanecido até o fim da II Guerra Mundial. Essa abordagem preconizava o desenvolvimento da leitura; logo, o trabalho com o léxico era considerado importante, e tratava-se de expandi-lo o mais rápido possível. Os exercícios mais usados para a aprendizagem da gramática eram os de transformação de frases e, ocasionalmente, utilizavam-se exercícios de tradução para a língua materna.

Após esse primeiro momento de rejeição da abordagem de gramática e tradução, foi elaborada nos Estados Unidos, ao longo dos anos 1950, a abordagem audiolingual, também conhecida como audiolingualismo, derivada dos princípios da linguística estrutural desenvolvidos por L. Bloomfield. Essa abordagem corresponde a um interesse maior pela forma do que pelo uso da língua, e objetiva o desenvolvimento de hábitos linguísticos. $\mathrm{O}$ trabalho do professor limita-se, em grande medida, à aplicação passiva e mecânica do modelo prescrito pelo método: introdução do novo material linguístico, com explicações gramaticais quando forem necessárias, e o controle da produção oral dos alunos mediante um procedimento de imitação e repetição.

De acordo com García (1995), surge, num momento posterior, a abordagem nocional-funcional, como reação a essa abordagem estrutural. Ela constitui o primeiro passo de uma corrente pedagógica, no campo do ensino de língua estrangeira, que se conhece como enfoque comunicativo ou ensino 
comunicativo de línguas. Essa abordagem privilegia as funçôes comunicativas que os usuários da língua utilizam em uma situação de interação verbal.

Segundo Santos Gargallo (1999), a abordagem comunicativa destaca o caráter funcional da língua como instrumento de comunicação, de maneira que são as funçóes linguísticas o foco da aprendizagem. Desse modo, introduz-se o conceito de competência comunicativa no âmbito do processo de ensino-aprendizagem de língua estrangeira. Hymes (1979) concebeu tal competência como a capacidade do usuário de empregar adequadamente a língua nas diversas situaçóes de comunicação: sua aplicação, nos diversos contextos de uso real da língua, considera que a linguagem deve ser apropriada a cada situação em que ocorre a comunicação e prioriza o interlocutor. Embora a abordagem comunicativa critique o uso da tradução direta no ensino de línguas, muitos adeptos dessa abordagem, como Costa (1988), Atkinson (1993), Ridd (2000), Romanelli (2009), Balboni (2011) e Widdowson (1991), pontuam a viabilidade do uso da tradução como técnica pedagógica.

$\mathrm{Na}$ contemporaneidade, dois fatores póem em destaque, novamente, a relevância do papel da tradução como estratégia ou procedimento no processo de ensino e aprendizagem de língua estrangeira. $\mathrm{O}$ primeiro aborda o estudo de aquisição de línguas a partir de um ponto de vista que destaca o papel da cognição. Nesse sentido, a tradução é considerada uma das estratégias cognitivas mais utilizadas pelos aprendizes de qualquer língua estrangeira, como observam O’Malley e Chamot (1990). O segundo é o recente - mas rápido - desenvolvimento dos Estudos de Tradução e Interpretação como disciplina autônoma. O surgimento da disciplina nos leva a repensar o papel da tradução como conteúdo dos programas de ensino de língua estrangeira, figurando como uma quinta habilidade a ser trabalhada, integrada às de compreensão e produção escritas e orais, no processo de ensino-aprendizagem. Na próxima seção, trataremos da importância da variação linguística no ensino de línguas.

\section{Variação linguística: da teoria ao ensino de línguas}

A Sociolinguística estuda a língua a partir do seu contexto social, com o objetivo de descrever como fatores linguísticos e extralinguísticos influenciam os fenômenos de variação e mudança inerentes às línguas. Os primeiros estudos da Sociolinguística Variacionista surgiram na década de 60, como reação 
à corrente proposta por Chomsky na década de 50 - a gramática gerativa, cujo objeto de estudo é a competência de um falante-ouvinte ideal pertencente a uma comunidade linguística homogênea. Segundo Bagno (2007), a Sociolinguística surgiu porque muitos cientistas nos Estados Unidos perceberam que não era possível estudar a língua desconsiderando a sociedade em que é falada, pois a língua não é homogênea e estável, mas está em constante mudança devido às interaçóes sociais. $\mathrm{O}$ estudo da variação a que nos ateremos foi impulsionado por William Labov, cujo modelo apresenta-se como reação à ausência do componente social no modelo gerativo e à homogeneidade e autonomia preconizadas pelo Estruturalismo. Labov (1972) diverge de Saussure e de Chomsky propondo o estudo da estrutura e da evolução da língua no contexto social da comunidade. Segundo Figueroa (1996, p. 71), quando se diz que a Sociolinguística é o estudo da língua em seu contexto social, isso não deve ser mal interpretado. A Sociolinguística laboviana não é uma teoria da fala, nem o estudo do uso da língua com o propósito exclusivo de descrevê-la, mas o estudo do uso da língua no sentido de verificar o que ela revela sobre a estrutura linguística. Quando Labov fala em heterogeneidade, refere-se à variação, mas está interessado na variação que pode ser sistematicamente explicada.

Foi, portanto, William Labov quem mais veementemente, como observa Tarallo (2005), voltou a insistir na relação entre língua e sociedade, e na possibilidade, virtual e real, de se sistematizar a variação existente e própria da língua falada. A língua é vista pelos sociolinguistas como dotada de "heterogeneidade sistemática”; a ausência de heterogeneidade estruturada na língua seria tida como disfuncional. Partindo do pressuposto de que a língua é heterogênea, concebemos o fenômeno de variação como uma realidade social. A variação significa a existência de distintas possibilidades para a expressão de uma determinada função linguística, ou seja, distintas estratégias, recursos linguísticos ou conjuntos de realizaçóes possíveis entre os recursos expressivos à disposição. Trata-se de escolhas linguísticas diversas que não afetam o processo de comunicação. Company Company (2003) destaca que a possibilidade de escolha entre uma forma linguística e outra ocorre geralmente: entre dois grupos de falantes; em um mesmo falante, com a possibilidade de escolha entre duas estruturas; na escolha de uma estrutura em uma determinada situação social comunicativa e de outra estrutura em outra situação comunicativa. 
De acordo com Labov (1978), as variantes constituem os diversos modos de se dizer a mesma coisa, ou seja, remeter ao mesmo estado de coisas, em um mesmo contexto de interação verbal. Os primeiros trabalhos de análise sociolinguística, que se concentravam no âmbito da Fonologia, evidenciaram que diferentes formas de comunicar, que compartilham o mesmo valor de verdade, apresentam diferenças no tocante aos valores sociais e estilísticos. Este fato dá abertura para críticas em relação à manutenção do mesmo significado nas variantes de uma mesma regra variável - questionamento explicitado em artigo por Lavandera (1978), que afirma que cada construção sintática possui seu significado próprio, sendo complicado substituir uma forma sintática por outra preservando o mesmo valor de verdade. Para a autora, o estudo sobre a variação linguística fora do âmbito da Fonologia fica comprometido. Ela propóe que a condição de mesmo significado seja ampliada para o que chama de comparabilidade funcional, na qual a existência em um mesmo espaço de formas alternantes ou a troca sequencial de uma forma por outra com o mesmo significado referencial não são livres nem totalmente condicionadas por fatores extralinguísticos, mas refletem uma escolha funcional do falante tendo em vista seus propósitos comunicativos. Lavandera critica, também, o fato de que muitas formas que estão fora do campo fonológico não sofrem influências sociais ou estilísticas, apenas linguísticas.

Para responder a essa questão, Labov (1978, p. 2) afirma que são variantes os enunciados que possuem o mesmo significado referencial, ou seja, o mesmo significado representacional ou estado de coisas: "dois enunciados que se referem ao mesmo estado de coisas têm o mesmo valor de verdade". O autor ratifica o princípio da equivalência semântica e destaca ser necessário que, como variantes de uma regra variável, se aceitem enunciados que possuam o mesmo valor de verdade, no mesmo contexto, mas não rigorosamente o mesmo significado. Seguindo esta lógica, pode haver diferenças em matizes de sentido, desde que o significado referencial não seja afetado. Labov separa o significado referencial em um nível, considerado como primário, e as funçóes de identificação do falante e de acomodaçáo do ouvinte em outro nível (secundário) que contemplaria os aspectos sociais e estilísticos. Dessa forma, variantes que portam diferenças de cunho pragmático podem ter o mesmo significado referencial. Labov (1978) argumenta, ainda, que a Sociolinguística é "sócio" não só porque lida com fatores estilísticos e sociais, mas por analisar a língua como componente social. 
Ao verificarmos o funcionamento de uma língua, percebemos que, nos diferentes contextos, ela apresenta-se de forma heterogênea, ou seja, apresenta variaçôes. Tarallo (2005) classifica essas variações como: diatópicas (diferenças em função do espaço geográfico); diastráticas (diferenças em função dos aspectos sociais como sexo, idade, etnia etc) e diafásicas (diferenças em função da utilizaçáo dos diversos estilos de linguagem na comunicação). Para o ensino de língua estrangeira, julgamos de vital importância o ensino desses três tipos de variação, principalmente, da variação diatópica, para que o aluno tenha conhecimento da ampla diversidade linguística.

Considerar o ensino de variantes é relevante porque, segundo Mollica (2007, p. 9), "todas as línguas apresentam dinamismo inerente, o que significa dizer que elas são heterogêneas". Além disso, a Sociolinguística interessa-se pela função social e comunicativa da língua, e vê a língua como fator importante na identificação de grupos e na demarcação de diferenças sociais na comunidade.

Bagno (2007), com base em estudos sobre o ensino da variação linguística, afirma que a maioria das gramáticas e dos livros didáticos de português limita-se à utilização de exercícios mecânicos de classificação e de análise sintática de estruturas, sem a devida contextualização para uma prática real de uso, o que revela uma concepção de língua estável e homogênea, distante da realidade linguística. $\mathrm{O}$ fato também é recorrente no ensino de língua estrangeira, conforme atestam pesquisas sobre o ensino da variação linguística em inglês e espanhol, tais como: Bugel (1999), Santos (2002, 2005), Rodrigues (2005), Kraviski (2007) e Pontes (2009). Essa prática leva o aluno à utilização mecânica das estruturas da variedade padrão, o que não necessariamente é o bastante no momento de produzir um texto, de adequar essas estruturas ao contexto de produção textual (gênero, suporte, tipo). Segundo Labov (1978), alunos norte-americanos que foram expostos durante toda a sua vida estudantil ao inglês padrão não conseguem reproduzi-lo com sucesso em uma entrevista de emprego de vinte minutos. Labov aponta que um dos fatores para este resultado é a desvalorização e até o preconceito por parte da escola com relação à variedade falada pelo educando. De acordo com Labov e Harris (1986, apud Bortoni-Ricardo, 2005, p. 181): "a simples exposiçấo a outro dialeto no domínio da escola ou pela mídia não acarreta mudanças no repertório básico de um falante". 
Segundo Bortoni-Ricardo (2004, p. 197), "os alunos devem sentir-se livres para falar em sala de aula e, independentemente do código usado - a variedade padrão ou variedades não-padrão, qualquer aluno que tome o piso em sala de aula deve ser ratificado como um participante legítimo da interação". Outra questão, levantada pela referida autora, diz respeito à correção do aluno por parte dos professores. Estes ficam inseguros e não sabem, na maioria dos casos, se devem corrigir ou até mesmo se é adequado falar em erros na sala de aula. Com relação a esse aspecto, Bortoni-Ricardo (2005, p. 42) propóe que: "diante da realização de uma regra não-padrão pelo aluno, a estratégia da professora deve incluir dois componentes: a identificação da diferença e a conscientização da diferença." Partindo da concepção de não-padrão como qualquer forma que não seja contemplada pela norma padrão, o professor pode realizar um trabalho de valorização das outras variedades, inclusive, da falada pelo aluno, para que este possa interagir em uma comunidade de fala.

Neste sentido, se pretendemos que nosso aluno conheça a diversidade linguística da língua que aprende, é necessário apresentar-lhe as distintas variedades, pois estas estão imersas nas diferentes culturas que falam uma língua, sendo a escolha das diferentes variantes um dos fatores que caracterizam os indivíduos em uma comunidade de fala. $\mathrm{Na}$ próxima seção, apresentamos algumas questóes sobre tradução, variação linguística e o ensino de línguas.

\section{Tradução, variação e ensino de língua estrangeira}

A ênfase na consciência ou awareness do aprendiz de uma língua pode ser apoiada pela tradução. O uso como procedimento implica que é mais enriquecedor, sob o ponto de vista didático, analisar os passos seguidos até se conseguir uma tradução, ou seja, precisamente o "processo" - mais que o produto propriamente dito. No lugar e momento oportunos, algumas atividades podem ativar a consciência do aprendiz no que diz respeito a elementos ou detalhes até então desconhecidos. Referimo-nos a exercícios como: a tradução inversa (back-translation); a explicação contrastiva a partir da tradução (por exemplo, a comparação formal de verbos em português e em espanhol, como gostar/gustar: Nós gostamos da tradução. / Nos gusta la traducción); a 
explicação de determinadas fórmulas lexicalizadas ou construçóes verbais mediante procedimentos de tradução; a simples tradução direta. No momento atual, as atividades de tradução realizadas em aulas de língua estrangeira são, geralmente, preparadas pelos professores da disciplina. Isso porque a maioria dos materiais didáticos publicados não inclui atividades de traduçáo - e, quando o faz, se limita a atividades de traduçáo direta, desconsiderando o contexto de produção do texto de origem. Os livros didáticos devem considerar a tradução, definitivamente, como procedimento didático no caso das aulas de língua estrangeira, e não limitá-la a um conceito ou conteúdo conceitual dos estudos específicos de tradução. Desse modo, o professor lançará mão de materiais complementares de acordo com o perfil e o contexto sociocultural do público a que se destina o livro, já que todo material didático apresentará lacunas e limitaçôes que deverão ser sanadas pelo docente, conforme argumenta Rodrigues (2005).

Destacamos as vantagens das atividades de tradução na aula de língua estrangeira, adaptadas de Mayoral (1998): a) sendo direcionada, reforça o trabalho com as quatros habilidades; b) ameniza o perigo das relaçóes unívocas, na medida em que se confere importância ao processo de tradução e não ao produto, e c) permite que se aproveite o caráter monolíngue dos alunos para comprovar a compreensão oral e escrita e para analisar as semelhanças e diferenças entre a língua materna e a língua estrangeira.

Vale destacar, ainda, que vários autores ressaltam a importância da variação linguística na atividade tradutória. Lefevere (1992) destaca o papel da variedade linguística para a tradução de uma situação específica, nas diferentes culturas. O autor enfatiza, ainda, os valores culturais e políticos que consolidam a prática e a investigaçáo tradutológica, reconhecendo a relevância da recuperação da variação sociolinguística no texto a ser traduzido. Hurtado Albir (1999) afirma que apresentar equivalências de palavras desconsiderando seu contexto deixa de proporcionar ao estudante a oportunidade de descobri-las em sua situação de uso, além de inibir o acesso a outros significados possíveis. Dessa forma, o aluno acaba por memorizar determinada tradução acreditando que ela funcionará sempre, independentemente do contexto. Segundo Agra (2007), traduzir não se reduz a uma atividade mecânica de transcodificação linguística, mas se trata de "desvendar" e interpretar o que está "por de trás" de uma palavra inserida num determinado contexto sociocultural, e que sen- 
tidos o vocábulo adquire naquela cultura. A autora destaca, ainda, que uma palavra tem seus significados socialmente construídos e que o tradutor deve considerar essa variável tâo relevante e decisiva no processo tradutório. M. Sneell-Hornby $(1988,1995)$ salienta a necessidade de existir um fundo sociocultural na atividade tradutora, defendendo que o enfoque seja interdisciplinar, com um lugar específico para a Sociolinguística. Para traduzir, é de vital importância interpretar e analisar não somente as estruturas lexicais e morfossintáticas, como também a situação pragmático-discursiva do texto a ser traduzido. Desse modo, uma análise sociolinguística poderá contribuir também para a ampliação do conhecimento no que tange ao contexto em que o material foi produzido.

As variedades de uma língua constituem uma abstração que pertence à situação específica de cada comunidade de fala de cada região, e não ao mundo material dos textos originais ou traduzidos. Nesse sentido, segundo Mayoral (1998), o tradutor se debruça sobre textos com determinadas marcas sociolinguísticas, e a tradução se ajusta tanto às especificidades quanto às exigências gerais da eficácia da comunicaçáo, para que o receptor possa compreender o contexto situacional traduzido de uma língua para outra. $\mathrm{Na}$ atividade tradutória, os encargos e os eventos comunicativos são únicos e estão submetidos a condicionamentos linguísticos e extralinguísticos. Logo, quem traduz deve estar atento às influências sócio-linguístico-culturais sobre a teoria e a prática da tradução, considerando os processos de variação e mudança linguísticas. A(s) língua(s) faladas pelas pessoas que intervêm em um processo de interação verbal não constituem apenas um elemento do contexto situacional a ser traduzido, mas também um meio de diferenciação social, regional, étnica ou geográfica (e mesmo sexual, em alguns casos), que permitirá a adoção de determinadas estratégias no momento de realizar a tradução da mensagem. $\mathrm{O}$ tradutor não pode estar alheio a esse complexo panorama de diversidade linguística, e deve ter em mente que em toda língua existe uma variedade denominada norma standard ou padrão, associada à ideia de língua homogênea descrita/prescrita pela gramática normativa. Essa variedade tem um papel unificador e busca neutralizar as variaçóes, tornando-se uma "referência suprarregional" (FARACO, 2002, p. 42). Ela é utilizada em situações de caráter mais formal, tem prestígio e é reconhecida como a variedade linguística que se utiliza nos meios de comunicação de difusão nacional, na escola e no ensino de línguas para estrangeiros. 
Certos tipos de textos, como os científicos, geralmente usam a variedade escrita e oral do standard (quase neutral) com uma clara marcação do campo de saber respectivo, mediante o uso de um tecnoleto (língua específica da área de estudo). Por outro lado, outros textos, como os literários ou de filmes e novelas a serem dublados ou legendados, podem apresentar os recursos expressivos (dialetais, socioletais, estilísticos, etc.) de uma variedade não padrão da língua, em clara oposição à pretendida neutralidade da norma standard. Nesse caso, o tradutor deve considerar as normas linguísticas próprias aos grupos sociais dos quais os personagens participam. Como estão ligadas a certos valores socioculturais, essas variedades apresentam características identitárias; além disso, elas se influenciam mutuamente, ou seja, são mescladas ou hibridizadas (cf. FARACO, 2002, p. 39).

Partindo desse pressuposto, o tradutor deve aprender a distinguir as diferentes variantes de uma língua. Por exemplo: para alguém que trabalhe com as combinaçóes inglês-espanhol ou espanhol-inglês, é importante saber distinguir quem está emitindo a mensagem (um norte-americano, um britânico, um jamaicano ou mesmo um suíço ou brasileiro falando em inglês, por exemplo). Essa distinção lhe permitirá saber que, para um norte-americano, candy é o mesmo que sweets para um britânico; ou, ainda, que playing noughts and crosses, para um britânico, é o mesmo que playing tic-tac-toe para um norte-americano. No caso das combinaçóes português-espanhol ou espanhol-português, é importante saber distinguir diferenças lexicais: para um chileno, por exemplo, guagua significa bebê, mas para um cubano significa ônibus.

Desse modo, no tocante ao ensino de língua estrangeira, partindo do pressuposto de que a variação linguística constitui uma realidade concreta na comunicação, caberia ao professor permitir que o aluno tivesse acesso às diferentes variedades da língua e soubesse em quais contextos sociais pode utilizar-se de cada variante, e não restringir o ensino da língua e a atividade tradutória a uma norma padráo desprovida de um contexto pragmático-discursivo. Assim, é requerida do professor uma preparaçáo que não se limite ao conhecimento estrutural da língua materna e da língua estrangeira. 


\section{Considerações finais}

O que defendemos é que se considere a tradução, definitivamente, como procedimento didático no caso das aulas de língua estrangeira e que a utilizemos como um dos recursos mais eficientes para estar permanentemente atento às diferenças em relação à língua e à cultura estrangeira. Nesse sentido, podemos sugerir que atividades de tradução aplicadas, no lugar e momento oportunos, podem ativar a consciência do aprendiz no que diz respeito a elementos ou detalhes até então desconhecidos. A tradução é uma oportunidade de termos acesso a outras culturas; e, sem a abordagem de fatos culturais em sala de aula, essa aproximação estaria limitada. No contexto educacional, a tradução pode ser utilizada pelos professores como uma quinta habilidade, a ser desenvolvida de forma integrada às demais, reconhecendo-se a importância da recuperaçâo da variaçáo linguística no texto a ser traduzido.

\section{Referências}

AGRA, A integração da língua e da cultura no processo de tradução. Biblioteca Online de Ciências da Comunicação, 2007, p. 1-18. www.bocc.ubi.pt/pag/ agra-klondy-integracao da lingua.pdf, 18/03/2013.

ATKINSON, David. Teaching Monolingual Classes. London: Longman, 1993. BAGNO, Marcos (org.). A linguística da norma. São Paulo: Loyola, 2002. p. 37-61. Nada na língua é por acaso: por uma pedagogia da variaçáo linguística. 1 ed. São Paulo: Parábola, 2007.

BALBONI, Paolo E. A tradução no ensino de línguas: história de uma difamação. Revista In traduçôes, v. 4, n. 1. Tradução de Maria Teresa Arrigoni. Florianópolis, Universidade Federal de Santa Catarina, 2011. http://www. pget.ufsc.br/ in traducoes/edicao_4/Traducao01-Difamacao_REVISADA. pdf,13/03/2013. BORTONI-RICARDO, S. M. Educação em Lingua Materna: a Sociolinguística na sala de aula. São Paulo: Parábola, 2004.

. Nós cheguemu na escola, e agora? Sociolinguística e Educação. São Paulo: Parábola, 2005.

BUGEL, T. O espanhol na cidade de São Paulo: quem ensina qual variante a quem? Trabalhos de Linguística Aplicada, 33, Campinas, Unicamp/IEL, 1999. COMPANY COMPANY, Concepción. "¿Qué es un cambio lingüístico", en COLOMBO, Fulvia y SOLER, María Ângeles (coords.). Cambio lingüistico y normatividad. México: UNAM, 2003. p. 13-32. 
COOK, G. Use of Translation in Language Teaching, en Baker, M., ed., Routledge Encyclopaedia of Translation Studies. Londres: Routledge, 1997. p. 117120. COSTA, Walter C. Tradução e ensino de línguas. In: BOHN, Hilário Inácio; VANDRESEN, P. Tópicos de Linguística Aplicada ao ensino de línguas estrangeiras. Florianópolis: Ed. UFSC, 1988. p. 282-291.

FARACO, Carlos Alberto. Norma-padrão brasileira: desembaraçando alguns nós. In: BAGNO, Marcos (org.). A linguistica da norma. São Paulo: Loyola, 2002. p. 37-61.

FIQUEROA, E. Sociolinguistic Metatheory. Language \& Communication Library. Vol. 14. Oxford: Pergamom, 1996.

HURTADO ALBIR, Amparo (dir.) Enseñar a traducir. Madrid: Edelsa,1999.

HYMES, D. H. On Communicative Competence. In: BRUMFIT, C. J. \& JOHNSON, K. The Communicative Approach to Language Teaching. Oxford: Oxford University Press, 1979.

KRAVISKI, E.R.A. Estereótipos culturais: o ensino de espanhol e o uso da variante argentina em sala de aula. Dissertação (Mestrado em Letras - Curso de Pós-Graduação em Letras, Universidade Federal do Paraná), Curitiba, 2007.

LABOV, W. Sociolinguistic patterns. Philadelphia: University of Pennsylvania Press, 1972a. __ Where does the Linguistic variable stop? A response to Beatriz Lavandera. Sociolinguistic Working Paper, 44. Texas, 1978.

Some Linguístics Principles. In: PAULSTON, C; TUCKER, G.R. (orgs.) Sociolinguistics: The essential readings. Massachusetts: Blackwell Publishing, 2003. LAVANDERA, B. Where Does de Sociolinguistics Variable Stop? In Language Society, Printed in Britain, 1978.

LEFEVERE, A. Translating Literature Practice and Theory in a Comparative Literature Context. Nova York: MLA, 1992.

LEFFA, Vilson J. Metodologia do ensino de línguas. In BOHN, H. In:VANDERSEN, P. Tópicos em linguistica aplicada ao ensino de linguas estrangeiras. Florianópolis: Editora da UFSC, p. 211-236, 1988.

MAYORAL, Roberto. La traducción de la variación lingüistica. Tesis doctoral. Universidad de Granada, Granada, 1998.

MOLLICA, Maria Cecília. Fundamentação teórica: conceituação e delimitação. In: MOLLICA, Maria Cecília; BRAGA, Maria Luiza (orgs.). Introdução à Sociolinguistica: o tratamento da variação. $3^{a}$ edição. São Paulo: Contexto, 2007, p. $09-14$. 
O’MALLEY, J. M. y A. U. CHAMOT. Learning Strategies in Second Language Acquisition. Cambridge UP, 1990.

PONTES, Valdecy de Oliveira. Abordagem das categorias verbais de tempo, aspecto e modalidade por livros didáticos de lingua portuguesa e de lingua espanhola: uma análise contrastiva. Monografia apresentada no Curso de Especialização em Linguística Aplicada da Faculdade 7 de setembro, Fortaleza, 2009.

RIDD, Mark David. Out of exile: a new role for translation in the teaching/ learning of foreign languages. In: João Sedycias. (Org.). Tópicos em Linguistica Aplicada/Issues in Applied Linguistics. 1 ed. Brasília, DF: Oficina Editorial do IL/Editora Plano, v. 1, p. 121-148, 2000.

RODRIGUES, D.S. O tratamento da variação linguistica em livros didáticos de Lingua Inglesa. 2005. 83f. Dissertação (Mestrado em Linguística Aplicada) - Curso de Mestrado Acadêmico em Linguística Aplicada, Universidade Estadual do Ceará, Fortaleza, 2005.

ROMANELLI, Sergio. O uso da tradução no ensino-aprendizagem das línguas estrangeiras. Revista Horizontes de Linguistica Aplicada, Brasília, DF, v. 8, n. 2, p. 200-219, 2009.

SANTOS GARGALLO, I. Lingüistica aplicada a la enseñanza-aprendizaje del español como lengua extranjera. Madrid: Arco/Libros, 1999.

SANTOS, H.S. O papel de estereótipos e preconceitos na aprendizagem de línguas estrangeiras. In: Anales del II congreso brasileño de hispanistas, 2002, São Paulo.

Quem sou eu? Quem é você? Será que a gente pode se entender? As representaçôes no ensinolaprendizagem do espanhol como lingua estrangeira. Dissertação de Mestrado defendida no Programa de Pós-Graduação em Língua Espanhola e Literaturas Espanhola e Hispano-Americana, DLM - FFLCH -USP. Inédita, 2005.

SNELL-HORNBY, M. Translation Studies. An Integrated Approach. Amsterdam John Benjamins Publishing Company.Philadelphia, 1988/1995.

TARAllO, Fernando. A Pesquisa Sociolinguística. 7a. Ed. São Paulo: Ática, 2005.

WIDDOWSON, H. G. O ensino de linguas para a comunicação. Tradução de José Carlos P. de Almeida Filho. Campinas: Pontes, 1991. 


\section{LA TRADUCCIÓN DE LA VARIACIÓN LINGÜÍSTICA Y LA ENSEÑANZA DE LENGUA EXTRANJERA: DE LA TEORÍA A LA PRÁCTICA DOCENTE}

\section{RESUMEN}

En este artículo, discutiremos las influencias sociolingüísticas de una sociedad sobre la teoría y la práctica de la traducción, teniendo en cuenta la enseñanza de lengua extranjera. En este trabajo, asumimos los aportes teóricos de los estudios sobre traducción, variación lingüística y enseńanza, propuestos por Labov (1972, 1978 y 2003), Mayoral (1998), Guy Cook (1997), O’Malley y Chamot (1990) y M. Sneell-Hornby (1988, 1995).

PALABRAS-CLAVE: Traducción; Sociolingüística; Enseñanza de Lenguas.

Recebido em: 27/08/2013 Aprovado em: 18/11/2013 